\title{
Application of ultrasonic simulation teaching in undergraduate teaching
}

\author{
Zheng Xin ${ }^{1 *}$, You Cheng Ming ${ }^{1}$, Zhang $\mathrm{Ce}^{2}$ and Song $\mathrm{Yu}^{3}$ \\ ${ }^{1}$ Department of anesthesiology, the second affiliated hospital of dalian medical university, China \\ ${ }^{2}$ Department of development and quality management, the second affiliated hospital of dalian medical university, China \\ ${ }^{3}$ Department of ultrasound, the second affiliated hospital of dalian medical university, China
}

\begin{abstract}
Point of care ultrasound (POCUS) has the advantage of timely, dynamic and radiation-free, POCUS has an excellent diagnostic and treatment accuracy many critical ill such as acute heart failure, pneumothorax, pulmonary edema, is most important diagnostic tool and can used as the initial clinical assessment for critical and emergency department. Simulation of point-of-care ultrasonography based education play a more important role in the education of medical students, can be used for anesthesia under-graduate students training to improve clinical skill rapidly. After standardized training, undergraduates can quickly use POCUS for evaluation of critical patients.
\end{abstract}

\section{Introduction}

At present, point of care ultrasound (POCUS) technology is widely developed in various clinical fields, which greatly promotes the development of related disciplines. Among them, critical care medicine was the first to introduce relevant technologies in China [1]. It actively carried out clinical practice, and proposed a series of optimized diagnosis and treatment processes based on relevant mature processes in foreign countries.

There are many common points between anesthesiology and critical care medical. Anesthesiology itself covers clinical anesthesia, critical disease monitoring, first aid resuscitation and pain treatment. It is a highly practical discipline, and its knowledge system includes a number of disciplines such as internal medicine, surgery, physiology, anatomy and pharmacology. By referring to critical care medicine and foreign experience [2-4], POCUS training in undergraduate teaching of anesthesia can rapidly improve undergraduate students' ability of clinical thinking and make rapid diagnosis simplification and visualization possible.

POCUS technology at present already had many mature process, such as diagnosis of dyspnea BLUE processes, the RUSH flow of the diagnosis of shock, the guide echocardiographic FATE processes in the chest and emergency trauma [5-7], FAST process has the characteristics of the operation is simple, rapid, and can rapidly complete the preliminary diagnosis of critically ill patients, severe discipline was founded in 2013 China's severe domestic ultrasound group 1, on the bedside ultrasound knowledge training, including basic training using the improved BLUE add FATE process CCUE process training and make intensive doctor quickly master bedside ultrasound evaluation techniques, It has a good reference value for anesthesia teaching.

Perioperative bedside ultrasound is widely used in European and American countries, especially in North America. European and American countries have tried to introduce POCUS course into undergraduate teaching, and the north American education system attaches great importance to the teaching of medical students' ultrasonic knowledge. According to statistics, $50 \%$ of Canadian medical schools and $62 \%$ of American medical schools have included bedside ultrasound courses in undergraduate students' teaching courses [8]. In comparison, the training of ultrasound programs in domestic teaching hospitals mainly focuses on nerve block and vascular puncture [9], and there are also reports of ultrasonic determination of gastric contents [10], which is more than the standardized training of residents, with a late start and a low starting point, and less involvement in real-time evaluation of perioperative patients. A small number of medical centers carry out transesophageal cardiac ultrasound (TEE) examination, and the medical centers that carry out TEE standardized training are currently only west China hospital, POCUS assessment content is generally not involved in undergraduate teaching. POCUS learning during undergraduate teaching can help undergraduate students have a preliminary understanding of the characteristics of bedside ultrasound, understand its advantages, and lay a solid foundation for further standardized training.

Teaching hospitals are responsible for the treatment and clinical teaching of critically ill patients. It is of great clinical significance to explore the rapid assessment process of perioperative POCUS to improve the prognosis of critically ill patients. Combined with years of undergraduate ultrasound teaching experience in anesthesia, the author is expected to have a beneficial impact on undergraduate teaching reform by following the CCUE simulation process of the training standard of severe ultrasound research group in China.

The CCUE process, Critical care ultrasound in emergencies, is a rapid assessment process for emergency patients that focuses on the cardiopulmonary system. According to the pulmonary ultrasound and cardiac ultrasound, 10 sections were selected for scanning in

${ }^{\star}$ Correspondence to: Zheng Xin, Department of Anesthesiology, The Second Affiliated Hospital of Dalian Medical University, China, E-mail: zhengxinxin008@163.com

Key words: point of care ultrasound, simulation education, under-graduate

Received: April 20, 2019; Accepted: April 28, 2020; Published: April 30, 2020 
turn to quickly assess the patients and exclude life-threatening critical conditions.

The department of anesthesia teaching and research in the second affiliated hospital of dalian medical university began to conduct POCUS training for undergraduate clinical interns in the department in January 2018. Referring to teaching experience in North America [8], the teaching mode of multimedia theory, hands-on teaching and small-class teaching is adopted, and the teaching mode of 3-4 students is adopted in each class. The teaching content is multimedia ultrasonic basic knowledge teaching, operation skills training for real person simulation teaching, models are healthy volunteers. The teaching teachers are all experts of ultrasound department. In the training of real person simulation operation, healthy volunteers are selected as standardized patients to be taught by ultrasound experts hand by hand, ensuring that each student has more than 30 minutes of one-on-one teaching time.

The assessment is divided into two parts. One round is conducted after the theoretical teaching, and five standard sections are required to be obtained within $5 \mathrm{~min}$. The second skill assessment after handson on-training is required to be the same as above. The results were rated by ultrasound specialists on acquisition time, standard section and anatomical identification.

Results after 2-3 months of short-term training, the students' operation level was significantly improved. The scores of theoretical assessment before and after the training are shown in Table 1. The actual operation assessment scores before and after the training are shown in Table 2 .

After the training, the feedback of the training results showed that all the students thought the bedside ultrasound simulation teaching had clinical significance. In terms of teaching improvement, $40 \%$ of the students think it is necessary to increase the training time of expert hands-on training, and 30\% think it is necessary to strengthen the training of basic ultrasonic knowledge. In short, through 4 weeks of simulation teaching training, undergraduates can complete the ultrasonic standard section scan, have a preliminary understanding of the advantages of bedside ultrasound, and have confidence in their own diagnostic ability.

The key to the change of anesthesiology to perioperative medicine is to improve the diagnostic ability. Bedside ultrasound provides an opportunity for the transformation of anesthesia discipline. POCUS technology has been proved in the practice of critical care medicine and emergency medicine to rapidly improve the diagnostic ability of

Table 1. The scores of theoretical assessment

\begin{tabular}{|c|c|c|c|c|}
\hline & $\begin{array}{c}\text { Numbers of } \\
\text { question }\end{array}$ & $\begin{array}{c}\text { Score before } \\
\text { training }\end{array}$ & $\begin{array}{c}\text { Score after } \\
\text { training }\end{array}$ & P \\
\hline Basic knowledge & 5 & $1.9 \pm 0.6$ & $4.6 \pm 0.3$ & 0.001 \\
\hline Lung ultrasound & 2 & $0.8 \pm 0.3$ & $1.7 \pm 0.5$ & 0.001 \\
\hline Cardic ultrasound & 8 & $2.7 \pm 1.1$ & $7.2 \pm 0.6$ & 0.001 \\
\hline total & 15 & $6.0 \pm 1.9$ & $13.6 \pm 1.3$ & 0.001 \\
\hline
\end{tabular}

Table 2. Practice assessment scores before and after training

\begin{tabular}{|c|c|c|c|c|c|}
\hline & $\begin{array}{c}\text { Correct } \\
\text { number of } \\
\text { cases before } \\
\text { training }\end{array}$ & $\begin{array}{c}\text { Accuracy } \\
\text { before } \\
\text { training (\%) }\end{array}$ & $\begin{array}{c}\text { Correct } \\
\text { number of } \\
\text { cases after } \\
\text { training }\end{array}$ & $\begin{array}{c}\text { Accuracy } \\
\text { after } \\
\text { training (\%) }\end{array}$ & P \\
\hline Pleural & 2 & 6 & 27 & 90 & $<0.001$ \\
\hline Diaphragm point & 1 & 3 & 30 & 100 & $<0.001$ \\
\hline Parasternal long axis & 2 & 6 & 25 & 80.3 & $<0.001$ \\
\hline $\begin{array}{c}\text { Four Chambers under } \\
\text { the xiphoid process }\end{array}$ & 1 & 3 & 29 & 97 & $<0.001$ \\
\hline
\end{tabular}

doctors in related disciplines. POCUS training period is short, and foreign studies have found that non-ultrasound doctors can make satisfactory interpretation of ultrasound images after 3 months of training. The program of process is an important guarantee for the implementation of bedside ultrasound. At present, the guidelines and operational guidelines for bedside ultrasound in the emergency department and the critical care department in China have been published. Also, as the hub department of the hospital, the anesthesia department should follow the situation and introduce the anesthesiarelated POCUS process. The anesthesia department can improve the ability of rapid perioperative diagnosis with the help of the favorable tool of bedside ultrasound. A large number of domestic and foreign literatures have confirmed that bedside ultrasound is no less effective in the diagnosis of acute pulmonary edema, heart failure, pneumothorax, pulmonary embolism and other life-threatening emergencies than CT and other imaging tools $[5-7,11]$, and it is also portable, repeatable, and radiation-free, with unique advantages in perioperative application. Moore said in an article in the New England journal POCUS stethoscope is the 21 st century, perioperative is the most important application fields of [12] POCUS, learn the knowledge make medical undergraduate students better qualified for future role, make the POCUS the perioperative patients with the clinical evaluation of core technology better service, and the anesthesiologist faster finish to perioperative doctor this historical mission.

\section{Funded project}

2019 teaching reform research project of dalian medical university (DYLX19026).

\section{References}

1. Wang Xiaoting, Zhang Hongmin, Liu Dawei (2018) Critical ultrasound: regulation and development. Chinese J Internal Med 57: 315-316.

2. Haskins SC, Feldman D, Fields KG, Kirksey MA, Lien CA, et al. (2018) Teaching a Point-of-Care Ultrasound Curriculum to Anesthesiology Trainees with Traditional Didactic Lectures or an Online E-Learning Platform: A Pilot Study. J Educ Perioper Med 20: E624.

3. Pietersen PI, Madsen KR, Graumann O, Konge L, Nielsen BU, et al. (2018) Lung ultrasound training: a systematic review of published literature in clinical lung ultrasound training. Crit Ultrasound J 10: 23.

4. Safavi AH, Shi Q, Ding M, Kotait M, Profetto J, et al. (2018) Structured, Small-group Hands-on Teaching Sessions Improve Pre-clerk Knowledge and Confidence in Pointof-care Ultrasound Use and Interpretation. Cureus 10: e3484.

5. Zanatta M, Benato P, De Battisti S, Pirozzi C, Ippolito R, et al. (2018) Pre-hospital lung ultrasound for cardiac heart failure and COPD: is it worthwhile? Crit Ultr J 10: 22.

6. See KC, Ong V, Tan YL, Sahagun J, Taculod J (2018) Chest radiography versus lung ultrasound for identification of acute respiratory distress syndrome: a retrospective observational study. Crit Care 22: 203.

7. Mullangi S, Sozio SM, Segal P, Menez S, Martire C, et al. (2018) Point $\square$ of $\square$ care ultrasound education to improve care of dialysis patients. Semin Dial 31: 154-162.

8. Arora S, Cheung AC, Tarique U, Agarwal A, Firdouse M, et al. (2017) First-year medical students use of ultrasound or physical examination to diagnose hepatomegaly and ascites: a randomized controlled trial. J Ultrasound 20: 199-204.

9. Yu Hong, Ze Peng, Yu Hai (2008) Perioperative ultrasound the basic skills of anesthesiologists in the new era. J Clin Anesth 34: 814-826.

10. Zhou Zhenfeng, Chen Long, Hu Shuangfei (2008) Establishment of ultrasonic qualitative gastric content learning curve for resident anesthesiologists in standardized training. Chinese J Med Educ 18: 107-112.

11. De Marchi L, Meineri M (2017) POCUS in perioperative medicine: A North American perspective. Crit Ultrasound J 9: 19.

12. Moore CL, Copel JA (2011) Point-of-care ultrasonography. N Engl J M 364:749-757.

Copyright: (C2020 Xin Z. This is an open-access article distributed under the terms of the Creative Commons Attribution License, which permits unrestricted use, distribution, and reproduction in any medium, provided the original author and source are credited. 